\title{
A REDESCOBERTA DA MATERNIDADE POR MULHERES VÍTIMAS DE VIOLÊNCIA DOMÉSTICA: UMA POSSIBILIDADE EXISTENCIAL
}

Liliana Maria Labronici ${ }^{1}$, Tatiane Herreira Trigueiro², Maria Lúcia Raimondo ${ }^{3}$, Débora Fegadoli ${ }^{4}$, Janete Maria da Silva

Batista $^{4}$

RESUMO: Trata-se de pesquisa qualitativa com abordagem fenomenológica, desenvolvida de outubro a dezembro de 2008, com cinco mulheres vítimas de violência doméstica residentes em uma casa abrigo de Curitiba, Estado do Paraná. Teve como objetivo desvelar o significado de ter morado em uma casa abrigo para mulheres vítimas de violência. Os discursos foram obtidos mediante entrevistas gravadas, e da sua análise emergiu o tema: A redescoberta da maternidade por mulheres vítimas de violência doméstica: uma possibilidade existencial. O caminho percorrido possibilitou perceber que as mulheres vítimas de violência têm dificuldade em se relacionar com seus filhos quando convivem com o agressor, porquanto a violência sofrida modifica o ser e estar no mundo, tornando-as agressivas e menos sensíveis; a maternidade é um papel que foi redescoberto e reaprendido porque as mulheres encontraram um ambiente harmonioso e acolhedor que propiciou a reflexão existencial entre passado e presente, e também o resgate da autoestima e autoimagem.

PALAVRAS-CHAVE: Enfermagem; Violência doméstica; Saúde pública.

\section{REDISCOVERY OF MOTHERHOOD BY WOMEN VICTIMS OF DOMESTIC VIOLENCE: AN EXISTENTIAL POSSIBILITY}

\begin{abstract}
This ia a qualitative research with a phenomenological approach, developed from October to December 2008 with five women victims of domestic violence living in a shelter house in Curitiba, Parana State. It aimed to reveal the meaning of having lived in a home shelter for women victims of violence. Data were collected through interviews, and by the analysis of its theme emerged the following category Rediscovery of motherhood by women victims of domestic violence: an existential possibility. The undertaken path made it possible to realize that women victims of violence have difficulty in the relation with their children when they live with the abuser, because the violent act modifies their being in the world, making them aggressive and less sensitive. Motherhood is a role and it was rediscovered and relearned because women have found a welcoming and harmonious environment that gave the existential reflection between past and present, and also the rescue of self-esteem and self-image.
\end{abstract}

KEYWORDS: Nursing; Domestic violence, Public Health.

\section{EL REDESCUBRIMIENTO DE LA MATERNIDAD POR MUJERES VÍCTIMAS DE VIOLENCIA DOMÉSTICA: UNA POSIBILIDAD EXISTENCIAL}

RESUMEN: Esta es una investigación cualitativa con abordaje fenomenológico, desarrollada de octubre a diciembre de 2008, con cinco mujeres víctimas de violencia doméstica que viven en una casa abrigo de Curitiba, estado de Paraná. Tuvo como objetivo desvelar el significado de haber vivido en una casa abrigo para mujeres víctimas de violencia. Los discursos fueron obtenidos por medio de entrevistas grabadas, y, de su análisis, emergió el tema: El redescubrimiento de la maternidad por mujeres víctimas de violencia doméstica: una posibilidad existencial. El camino posibilitó percibir que la mujer víctima de violencia tiene dificultad en relacionarse con sus hijos cuando conviven con el agresor, ya que la violencia sufrida cambia el ser y estar en mundo, tornándola agresiva y menos sensible; la maternidad es un papel que fue redescubierto y reaprendido porque las mujeres encontraron un ambiente armonioso y acogedor que ha propiciado la reflexión existencial entre pasado y presente, y también el rescate de la autoestima y de la autoimagen.

PALABRAS CLAVE: Enfermería; Violencia doméstica; Salud pública.

${ }^{1}$ Enfermeira. Doutora em Enfermagem. Professor Adjunto do Departamento de Enfermagem e do Programa de Pós-Graduação em Enfermagem da Universidade Federal do Paraná-UFPR. Líder do Grupo de Estudos Multiprofissional em Saúde do Adulto-GEMSA/UFPR. ${ }^{2}$ Enfermeira. Mestranda em Enfermagem do Programa de Pós-Graduação em Enfermagem da UFPR. Membro do GEMSA/UFPR. Bolsista PROF.

${ }^{3}$ Enfermeira. Mestranda em Enfermagem pelo Programa de Pós-Graduação em Enfermagem da UFPR. Professora da Universidade Estadual do Centro Oeste-UNICENTRO. Membro do GEMSA/UFPR. Membro do Núcleo de Estudos e Pesquisa Sobre Violência Urbana-NEVU/ UNICENTRO. Bolsista Fundação Araucária.

${ }^{4}$ Enfermeira. Mestranda em Enfermagem do Programa de Pós-Graduação em Enfermagem da UFPR. Membro do GEMSA. Bolsista REUNI.

Autor correspondente:

Liliana Maria Labronici

Universidade Federal do Paraná

Rua Pe. Camargo, 120 - 80060-240 - Curitiba-PR, Brasil Recebido: 16/11/09

E-mail: lililabronici@yahoo.com.br

Aprovado: 10/08/10

Cogitare Enferm. 2010 Jul/Set; 15(3):474-9 


\section{INTRODUÇÃO}

O estar no mundo possibilita vivenciar uma multiplicidade de fenômenos que deixam marcas na existência humana. Entre eles podemos mencionar a violência contra a mulher, que pode se manifestar em diferentes ambientes, em todas as fases da vida e classes sociais, ser desencadeada por diversos fatores, e afetar em suas múltiplas dimensões.

No Brasil, dois milhões de mulheres adultas são violentadas por ano ${ }^{(1)}$, e em Curitiba, no período de 2003 a 2006, foram notificados 2.467 casos de violência contra mulheres, dos quais 1.872 foram de violência sexual, 548 física, 295 verbal e 256 psicológica $^{(2)}$.

As consequências físicas ocasionadas pela violência sofrida pelas mulheres podem ser: abortos, cefaleias crônicas, dores abdominais, dores musculares, lesões permanentes, problemas ginecológicos e agravos à saúde mental, como ansiedade generalizada, abuso de álcool e drogas, tentativas de suicídio, transtorno pós-traumático e depressão ${ }^{(1)}$. Desta forma, além de ser considerada como violação de direitos humanos, a violência é um fenômeno que propicia agravos à saúde e requer, como política de intervenção social, ações de caráter interdisciplinar e intersetorial, compondo-se de redes assistências direcionadas à saúde, à segurança pública e pessoal, à justiça e ao bem-estar social ${ }^{(3)}$.

Importante se faz destacar que a Lei n. 11.340denominada Lei Maria da Penha - desde 2006 fornece bases legais para a assistência à mulher em situação de violência doméstica e familiar, e estabelece assistência integrada e articulada, conforme os princípios e as diretrizes previstas na Lei Orgânica da Assistência Social, no Sistema Único de Saúde e no Sistema Único de Segurança Pública, em uma ação articulada entre as esferas do governo federal, estadual e municipal ${ }^{(4)}$.

No ano de 2006, com o objetivo de organizar redes integradas de atenção às vítimas de violência em conjunto com as Secretarias Estaduais e Municipais de Saúde, o Ministério da Saúde elaborou a Norma Técnica para a atenção integral a mulheres e adolescentes em situação de violência doméstica, e delega aos estados e municípios essa responsabilidade, assim como a implantação e manutenção de serviços voltados para a saúde, assistência social, educação e segurança, a fim de assistir às vítimas de violência na rede pública ${ }^{(5)}$.

Em Curitiba, a Secretaria Municipal da Saúde desde 2002, vem desenvolvendo o Protocolo de Aten- ção à Mulher em Situação de Violência, que organiza o fluxo de atendimento da mulher ao longo da rede de assistência composta pelas Unidade de Saúde e os serviços de referência hospitalar, o Centro de Referência à Mulher, a Delegacia Especializada da Mulher e o Juizado de Violência Doméstica e Familiar Contra a Mulher. Esta rede conta com uma casa abrigo, para onde as mulheres que necessitam de proteção são encaminhadas $^{(2)}$.

Diante do exposto, esta pesquisa teve como objetivo desvelar o significado de ter morado em uma casa abrigo para mulheres vítimas de violência.

\section{MATERIAL E MÉTODO}

Trata-se de pesquisa qualitativa de abordagem fenomenológica, e esta opção ocorreu porque a fenomenologia possibilita a investigação da existência do ser humano numa determinada situação, e de seu modo particular de atribuir significados aprisionados na consciência e chamados de fenômenos. Estes são percepções ocultas que podem ser desveladas, descobertas pelo pesquisador livre de valores, crenças, pressupostos e pré-conceitos ${ }^{(6)}$.

A pesquisa foi desenvolvida em uma casa abrigo, no período de outubro a dezembro de 2008. Esta integra a rede de assistência à mulher vítima de violência do Município de Curitiba, mantida pela Fundação de Ação Social (FAS). A casa foi implantada no ano de 1993, para garantir o atendimento às necessidades trazidas por essa população em caráter protetivo e transitório.

A casa abrigo atende mulheres acima de 18 anos, acompanhadas ou não de seus filhos, e que são encaminhadas pelos Núcleos Regionais, Centrais de Atendimento Social, Delegacia da Mulher, Conselhos Tutelares, Vara da Família, Conselho Municipal da Condição Feminina e Unidades de Saúde. Tem como objetivo reinserir a mulher, através da retomada de sua vida, ao convívio familiar e social, de forma que possa refazer sua história na sociedade ${ }^{(7)}$.

Pesquisa realizada na casa abrigo, possibilitou constatar que no período de 1993 a 2007 as mulheres vítimas de violência tinham idade entre 18 e 88 anos, viviam em união consensual, com baixo nível de escolaridade, sofreram violência física, psicológica, sexual e estrutural, e os agressores eram, principalmente, seus companheiros ${ }^{(8)}$.

Fizeram parte da presente pesquisa todas as mulheres que, no período da coleta dos discursos, 
residiam na casa abrigo. Aceitaram o convite e oficializaram a participação mediante assinatura do termo de consentimento livre e esclarecido. Desta forma, o total de participantes foram cinco mulheres.

A coleta dos discursos ocorreu por meio de entrevista aberta, gravada, transcrita na íntegra e analisada à luz da fenomenologia, porquanto esta possibilita a descrição do fenômeno vivenciado. A descrição da experiência vivida surge a partir de uma ou mais questões para incitar o outro a falar, e nesta pesquisa a solicitação inicial da entrevista foi: Faleme o que foi, para você, ter morado temporariamente nesta casa abrigo.

No que diz respeito aos aspectos éticos, o projeto obteve autorização da Fundação de Ação Social, e foi aprovado pelo Comitê de Ética do Setor de Ciências da Saúde da Universidade Federal do Paraná (CAAE 1083.0.000.091-07).

$\mathrm{O}$ anonimato das participantes foi garantido por meio da utilização da abreviatura "E" de entrevistada, seguida por numerais arábicos, em ordem crescente, conforme explicitado: E1, E2, E3, E4 e E5.

Os discursos foram analisados mediante três momentos: descrição, redução e compreensão ${ }^{(9)}$. A descrição na pesquisa fenomenológica é a exposição de um fenômeno que assume a forma de texto à espera de análise, interpretação e compreensão. A redução consiste em procurar na descrição da entrevista fragmentos do discurso, ou seja, unidades de significado que podem apontar para o desvelamento do fenômeno. Já a compreensão fenomenológica surge em conjunto com a interpretação, e só é possível quando o pesquisador desvela a consciência que o sujeito tem do fenômeno ${ }^{(10)}$.

Uma vez encontradas as unidades de significado convergentes, em todas as descrições, o pesquisador faz a interpretação de cada entrevista por meio de linguagem própria, e, em seguida, faz a síntese, gerando as unidade(s) temática(s) ${ }^{(10)}$.

A unidade temática encontrada nesta pesquisa foi: A redescoberta da maternidade por mulheres vítimas de violência doméstica: uma possibilidade existencial.

\section{RESULTADOS E DISCUSSÃO}

O existir humano é permeado, desde o nascimento até a morte, por uma multiplicidade de fenômenos que são vivenciados e possibilitam a atribuição de significados. Entre eles encontramos a violência doméstica, um fenômeno existencial que afeta o ser e estar no mundo da mulher, deixa marcas visíveis e invisíveis, e se revela como algo brutal para a nossa sociedade.

Reconhecer o invisível no visível, no concreto da existência humana, o corpo compreendido como o primeiro e único lugar da experiência humana, exige postura de abertura e flexibilidade, olhar hermenêutico, capaz de transcender o biológico e captar, pela percepção, o vivido e seus significados. Dessa forma, é possível ver o outro em sua totalidade que é constituída por múltiplas dimensões, desvelar significados, e também, no contexto da prática profissional, entrelaçar ações técnicas e expressivas, de modo a proporcionar um cuidado ético, solidário e humanizado ${ }^{(11)}$.

Penetrar na subjetividade humana mediante a olhar hermenêutico significa perceber aquilo que se mostra e está diante de nós. Neste sentido, a percepção desencadeia todo o processo de descoberta e de conhecimento, fornece uma camada de impressões que estão carregadas de sentido, e possibilita desvelar significados existenciais a partir da intencionalidade, mas que também deixam lacunas ${ }^{(11)}$.

A intencionalidade levou-nos a definir o objetivo desta pesquisa, a partir do vivido pelas mulheres, porque o vivenciado pode fornecer elementos que poderão ajudar na melhoria da assistência recebida, vez que a casa abrigo, enquanto espaço de acolhimento, aproximação e promoção da cultura da paz entre mães e filhos, deve garantir abrigo e dar proteção não apenas à mulher em situação de violência, mas a seus filhos menores de $12 \operatorname{anos}^{(2)}$. Neste sentido, as falas de algumas participantes revelaram as dificuldades no relacionamento, conforme evidenciado nos fragmentos dos seguintes discursos:

Antes eu era nervosa, e agressiva até com meus filhos, porque os problemas vão te deixando nervosa [...]. (E2)

Antes de vir pra cá eu era muito ansiosa, parecia que eu tinha medo, medo do meu ex-marido. Depois que eu vim pra cá eu melhorei sobre meus filhos, porque eu sempre fui mais de gritar e até surrar, e eu vi que o castigo é a melhor coisa. Meus filhos tão bem educadinhos, antes eram meio revoltados. Eu mudei, aprendi a ser mais calma, a ser feliz [...]. (E3)

A interação mãe-filho é uma relação existencial que depende de fatores internos e externos ${ }^{(11)}$. Neste sentido, um ambiente livre de ameaças, agressões 
e do estresse pós-traumático propicia uma vivência harmoniosa, uma aproximação que possibilita o fortalecimento dos vínculos, vez que o amor materno não é uma condição inata à mulher, mas uma relação que se constrói com o passar do tempo em que o binômio mãe-filho interage. Essa construção pode ser influenciada pelas determinações da subjetividade social e cultural de cada mulher ${ }^{(12)}$.

A afetividade é indispensável na existência humana, e a sua ausência pode trazer implicações significativas nas relações interpessoais, manifestadas no comportamento de embotamento emocional, bem como pode exacerbar sentimentos agressivos ${ }^{(13)}$.

As relações interpessoais representam o alicerce para a formação da identidade da criança, e a família é a principal responsável para fornecer a base formadora, com proteção e segurança. Contudo, quando as expõe a uma realidade violenta, os sentimentos, as avaliações e as interpretações acerca de si mesmas, do outro e do mundo em que vivem, se expressam de maneira negativa no seu estar no mundo ${ }^{(14)}$.

Os processos proximais são mecanismos constituintes dessa interação da criança com o adulto e outras crianças, contribuem para que desenvolvam sua percepção, dirijam e controlem seu comportamento, além de possibilitar aquisição de conhecimentos e habilidades, de modo a estabelecer relações e construir seu próprio ambiente físico e social ${ }^{(15)}$.

Um ambiente onde os conflitos, a agressão e a não-harmonia se fazem presentes, gera hostilidade, interfere no convívio familiar, e, consequentemente, no modo de ser e estar no mundo de cada um, principalmente das crianças. Estas estão na fase de crescimento e desenvolvimento da personalidade, e vivenciam uma experiência traumática em sua trajetória existencial, marcada pela inquietação diante do perigo, da ameaça, enfim, pelo medo.

O sair do ambiente hostil e vivenciar um espaço em que a violência não está presente pode propiciar um cotidiano mais ameno, e com possibilidades existenciais que poderão ajudar no reequilíbrio da totalidade humana. Tal é o cenário da casa abrigo, no qual todos os atores sociais que compõem a equipe realizam atendimento de modo acolhedor. Isso foi possível de constatar, mediante os fragmentos de discurso:

[...] agora tô mais calma. Acho que aqui eu aprendi a controlar[...]. (E2)

Eu tô mais sossegada. Tenho mais calma, que eu não tinha. Tenho mais paciência e devagarzinho to dando melhor de mim pros meus filhos [...]. (E5)

O acolhimento modifica o ser e estar no mundo das mulheres vítimas de violência doméstica, porque ao oferecer um ambiente saudável e harmonioso, possibilita a libertação gradativa do comportamento agressivo, que de certa maneira, é um mecanismo de defesa e proteção contra o medo e os fantasmas produzidos que as atormentam. $\mathrm{O}$ acolhimento faz com que se sintam seguras, porque são tratadas com respeito, dignidade, sem preconceito.

A harmonia que permeia a casa abrigo incita o projetar-se da mãe em direção ao filho, um movimento de aproximação, e que as faz realizar um balanço existencial e refletir na temporalidade entre passado e presente $^{(11)}$, e reconhecer o distanciamento vivido no ambiente hostil em que a violência se fazia presente, conforme evidenciado nos fragmentos dos discursos:

[...] antes eu não tinha tempo com meus filhos e hoje eu tenho [...]. (E1)

[...] aqui eu aprendi a controlar, e a estar mais perto dos meus filhos [...]. Agora quero começar a trabalhar e viver minha vida, cuidar dos meus filhos e apagar tudo isso que aconteceu. Acho que nisso eu mudei, porque aqui eu comecei a pensar. Aqui você tem mais tempo pra pensar, em casa você não tem [...]. (E2)

[...] depois que eu vim pra cá dei mais valor pros meus filhos. Arrumam o quarto, tomamos café juntos, lavo roupa, ajudo as outras mães pra depois vir dormir do trabalho, ai vou trabalhar alegre, feliz. Antes eu brigava muito com as crianças, não tinha paciência com eles [...]. (E4)

[...] agora com meus filhos tá bem melhor do que antes, agora eu tô junto com eles direto, 24 horas por dia [...]. Brinco com eles, cuido bem deles, porque antes eu não fazia isso direito [...]. (E5)

A tomada de consciência propiciada pela reflexão modificou o ser e estar no mundo das mulheres, ao reconhecerem a falta de tempo para cuidar dos filhos, o distanciamento, a relação não harmônica, e a importância de estar-com efetivamente.

O estar com o outro pressupõe interação, pode ser compreendida como uma relação existencial que faz parte do mundo ${ }^{(11)}$, e quando envolve o binômio 
mãe-filho, requer mais atenção, visto que faz parte do papel de ser mãe.

A maternidade, enquanto uma misteriosa e fantástica aventura existencial, é um dos muitos espetáculos que propiciam prazer à mulher, que, ao entrar neste novo ciclo, passa a vivenciar outro tipo de amor: o amor materno ${ }^{(11)}$. Este, como todos os sentimentos humanos, é frágil, incerto e imperfeito, e não está inscrito na natureza intrínseca da mulher, vez que é adquirido mediante a convivência e os cuidados cotidianos que são prestados à criança durante seu desenvolvimento ${ }^{(12)}$.

Ser mãe é um papel que necessita ser estimulado, aprendido e exercitado, para que a mulher possa desenvolver este novo status social. É uma construção humana mutável, constituída por padrões de comportamento que se modificam de tempos em tempos, e afasta a ideia de ser uma tendência natural ${ }^{(16)}$.

As mulheres vítimas de violência doméstica deste estudo sabiam que eram mães, mas a experiência vivida temporariamente na casa abrigo possibilitou um olhar diferente sobre o ser mãe, conforme explicitado a seguir:

Agora eu sou mais mãe. Eu vi que ser mãe é bem diferente. Aqui eu aprendi a ser mãe. Eu vou chegar em casa e vou ser a mãe deles, vou cuidar, vou ajudar, vou buscar no colégio [...]. (E1)

[...] aprendi a estar mais perto dos meus filhos [...] começar a cuidar dos meus filhos e apagar tudo isso que aconteceu. (E2)

[...] hoje eu fico mais com meus filhos [...]. Tudo que eu tenho de bom para oferecer pros meus filhos, hoje, uma conversa, uma educação, acho que eu devo à casa abrigo [...]. Aprendi a lidar com meus filhos [...]. (E3)

Eu não tinha muito amor pelas crianças. Hoje sou totalmente diferente com meus filhos. Agora que tô me acordando, que tô começando a dar mais amor pros meus filhos. Tô gostando mais dos meus filhos, amando mais eles, então isso pra mimé uma grande mudança. Tudo isso porque eu tô aqui e eu ainda quero mudar muito mais, e se Deus quiser eu vou mudar. (E5)

As falas deixaram explícito que, apesar de serem mães, as formas como desempenhavam o papel da maternidade não eram adequadas, e isso provavelmente porque estavam imersas em um ambiente no qual predominava a violência familiar, incluindo a negligência em relação às crianças.

As mulheres vítimas de violência doméstica, ao viverem temporariamente na casa abrigo, perceberam a importância do papel de ser mãe. Este possibilita uma das formas de expressão de existência concreta no mundo, que as faz renascer para a vida na medida em que o ser-mulher emerge na experiência cotidiana, e se manifesta no cuidado e na afetividade para com seus filhos ${ }^{(17)}$.

O resgate da maternidade como possibilidade existencial se expressa mediante sua subjetividade em alcançar um ideal imposto pela sociedade que considera a maternidade um potencial humano maior e o cuidado dos filhos uma atividade nobre. Esta redescoberta do papel de ser mãe permite a reconstrução da sua identidade como ser mulher em relação com o mundo, consigo mesma e com os outros ${ }^{(18)}$.

A redescoberta da maternidade enquanto possibilidade existencial foi propiciada pela vivência adquirida na casa abrigo, porquanto é um ambiente acolhedor, no qual seus constituintes possuem postura de abertura e flexibilidade. Esse ambiente favorece a relação entre elas, bem como a aproximação mãe/ filho, de forma a fortalecer os vínculos afetivos necessários para o desenvolvimento da criança.

A partilha de emoções positivas e as trocas afetivas com as crianças fazem com as mulheres se sintam emocionalmente seguras, com capacidade de expressar sentimentos adequados e regular emoções negativas no contexto das relações, o que não é possível quando a mãe tem uma relação conjugal negativa, hostil, permeada por conflitos e violência, e que não propicia o estímulo de sentimento de afeto e valorização.

\section{CONSIDERAÇÕES FINAIS}

A pesquisa em tela possibilitou perceber que as mulheres vítimas de violência têm dificuldade em se relacionar com seus filhos quando convivem com o agressor, porquanto a violência sofrida modifica o ser e estar no mundo, de modo a torná-las também agressivas, menos sensíveis. Assim, a forma de expressarem sua existência, enquanto estão sob o mesmo cenário do agressor, ocorre mediante diversas maneiras como a prática de maus tratos e a negligência para com os filhos, o que se configura também como violência.

Adentrar na casa abrigo com os filhos foi para as mulheres vítimas de violência doméstica encontrar 
um cenário no qual o ambiente harmonioso e acolhedor propiciou a reflexão existencial entre passado e presente. $\mathrm{O}$ ser e estar no mundo na temporalidade, do aqui e agora em um ambiente livre de hostilidade e ameaças, foi fundamental para que as mulheres olhassem para dentro de si e percebessem a importância do papel de ser mãe.

A redescoberta da maternidade, no sentido de viver este papel de modo diferente daquele anteriormente vivido, foi possível em função do atendimento oferecido pela equipe da casa abrigo. Assim, a casa parece ser uma passagem, uma travessia que mostra algumas possibilidades existenciais que poderão modificar o ser e estar no mundo das mulheres que por ali passaram.

\section{REFERÊNCIAS}

1. Secretaria Especial de Políticas para as Mulheres. Enfrentamento à violência contra a mulher: balanço de ações 2006-2007. Brasília, 2007.

2. Secretaria Municipal de Saúde. Atenção à mulher vitima de violência. Curitiba, 2008.

3. Schraiber LB, D’Oliveira AFPL, França Júnior I, Diniz S, Portela AP, Ludermir AP, et al. Prevalência da violência contra a mulher por parceiro íntimo em regiões no Brasil. Rev Saúde Pública 2007;41(5):797-807.

4. Brasil. Decreto n. 11.340 de 7 de agosto de 2006 . Cria mecanismos para coibir a violência doméstica e familiar contra a mulher. Diário Oficial da União. [Internet] 07 ago 2006 [acesso em 02 jan 2010]. Disponível: http://tiny.cc/10osj

5. Ferraz MIR, Labronici LM. Perfil da violência doméstica contra mulher em Guarapuava, Paraná. Cogitare Enferm. 2009;14(2):261-8.

6. Camatta M, Nasi C, Schaurich D, Schneider J. Contributions from Alfred Schütz's phenomenological sociology for nursing research - review article Online Braz J Nurs. [Internet] 2008;7(2). [acesso em 05 mai 2009] Disponível: http://tiny.cc/dal7c

7. Fundação de Ação Social. Abrigo para mulheres vítimas de violência. Curitiba: FAS; 2007.p.2.

8. Labronici LM, Ferraz MIR, Trigueiro TH, Fegadoli D. Perfil da violência contra mulheres atendidas na Pousada de Maria. Rev Esc Enferm USP. [Internet]. 2010;44(1) [acesso em 05 jul 2010] Disponível: http:// tiny.cc/s95jh. doi: 10.1590/S0080-62342010000100018
9. Martins J. Um enfoque fenomenológico do currículo: educação como poíesis. São Paulo: Cortez; 1992.

10. Albini L, Labronici LM. Exploitation and alienation of the body of the nurse: a phenomenological study. Acta Paul Enferm. [Internet] 2007;20(3). [acesso em 05 abr 2009] Disponível: http://tiny.cc/0t105

11. Labronici LM. Eros propiciando a compreensão da sexualidade das enfermeiras [tese]. Florianópolis (SC): Universidade Federal de Santa Catarina; 2002.

12. Badinter E. Um amor conquistado: o mito do amor materno. Rio de Janeiro: Nova Fronteira; 1985.

13. Oliveira AMN, Loch GM, Lopes FL, Silva, LWS. A relação de afeto/desafeto em famílias de crianças com comportamento agressivo. R Pesq Cuid Fundam. Online. [Internet] 2005;9(1/2) [acesso em 05 jul 2010]. Disponível: http://tiny.cc/glpws

14. Szymanski H. Práticas educativas familiares e o sentido da constituição identitária. Paidéia. [Internet] 2006;16(33) [acesso em 05 jul 2010]. Disponível: http:// tiny.cc/pw2ox

15. Andrade SA, Santos DN, Bastos AC, Pedromônico MRM, Almeida N, Barreto ML. Ambiente familiar e desenvolvimento cognitivo infantil: uma abordagem epidemiológica. Rev Saúde Pública. [Internet] 2005;39(4) [acesso em 02 mai 2009] Disponível: http:// tiny.cc/f6clx

16. Soares JS, Carvalho, AM. Mulher e mãe, "novos papéis", velhas exigências: experiência de psicoterapia breve grupal. Psicol Estud. 2003;(8):39-44.

17. Nascimento MGP. Significado de ser-mãe uma abordagem existencial [tese]. Florianópolis (SC): Universidade Federal de Santa Catarina; 2002.

18. Maux AAB, Dutra E. Do útero à adoção: a experiência de mulheres férteis que adotaram uma criança. Estud Psicol. [Internet] 2009;14(2) [acesso em 04 jul 2010]. Disponível: http://tiny.cc/mo8lq 